\title{
Regeneration of Industrial Buildings Xiamen Huli District ---A Case Study of Huamei Cigarettes Factory Reconstruction
}

\author{
Maole $\mathrm{Ye}^{1, \mathrm{a}}$, Bo Lin ${ }^{1, \mathrm{~b}}$ \\ ${ }^{1}$ Xiamen University Tan kah Kee College, Longhai, Fujian, 363105 \\ ayemaole@xujc.com, ${ }^{b}$ wellyuki@xujc.com
}

Keywords: Xiamen Huli District; Industrial Buildings, Regeneration;

\begin{abstract}
With the "retreat into three" to promote industrial restructuring and upgrading, Huli district of Xiamen City, regeneration and transformation of industrial buildings is imperative. Huamei Cigarettes Factory as the larger regional warehouses, methods and ways of its transformation directly affects the rehabilitation and upgrading of other idle industrial buildings. By integrating space law, primary and secondary antitheses, facade induction, structural performance method, continuation method for memory space Huamei design techniques and ideas to explore and summarize, in order to facilitate the idle of Huli district industrial buildings transformation and metamorphosis.
\end{abstract}

\section{Introduction}

As the birthplace of Xiamen Special Economic Zone, Huli District, the old industrial area has made great contributions to the positive development of Xiamen and opened a new chapter in economic development [1]. 30 years ago, the Huli streets and the Xiamen Special Economic Zone was born, along the Huli Avenue gathered the first development and construction of the industrial plant, bred the King Long, xосесо, Golden Heron and a large number of Xiamen key industrial enterprises. However, with the industrial optimization and transformation of Xiamen, some of the traditional extensive processing and pollution of the enterprise gradually eliminated, and began to adjust the production base to low-cost suburbs or inland. Huli Road, Xiamen, the old industrial plant is a new round of urban transformation of the key areas, but also the economic engine Huli District.

\section{Introduction to the Concept of Creative Industries}

With the industrial transformation and upgrading of Huli District, the development of cultural and creative industries has become the focus of the direction of transition ${ }^{[2]}$. Into the era of knowledge economy, cultural and creative industries are at an alarming pace in the global rapidly rise to become the pillar industries of many developed countries and regions, which attracted the attention of various national and regional governments.

As a late start of the city, Xiamen creative industry development is slow, still tourism and industry as the key industry. With the industrial transformation and renewal, Huli District along with the closure of some industrial plants or transfer, leaving a need to be updated and renewable plant. Through the inspection, research and analysis, as a low pollution, high value-added cultural and creative industries have become the focus of the transformation of the old industrial zone development direction. In August 2012, Fujian and Taiwan Cultural Industry Experimental Park after many rounds of selected projects in the many projects to stand out as the fourth batch of national cultural industry, one of the pilot park. Fujian and Taiwan Cultural Industry Experimental Park, the core area is located in the old industrial area in Huli District, the planned land area of 650,000 square meters. At the same time, the Xiamen Municipal Government has also introduced a series of preferential policies and measures, for example, subsidies for the transformation of the old plant, the cultural and business enterprises to be rented subsidy assigned to the stationed in the text of the master and industry leaders to subsidize and reward. 


\section{Modification Practice of Huamei Cigarette Factory}

Old industrial buildings engraved with the history of the development of urban industrial civilization, the past, the noise and roar of machinery and equipment, along with urban renewal, industrial restructuring, factory relocation, has become the glory of yesteryear ${ }^{[3]}$.

Huamei Cigarette Factory is not the first dare to break through and try in the transformation of industrial buildings in Huli district. At the same time, the introduction of diversified industry content and enrich the cultural and creative park as an office service park in the form of respect and transformation of the original space form On the basis of bold innovation into the modern design of the fashion, exaggeration, novel design ideas, greatly enhance the Huli District, the creation of space for space design quality space.

Huamei space is the first Sino-foreign joint-venture cigarette enterprise in China - Huamei Cigarette Factory. The project covers an area of 42,000 square meters and a construction area of 55,000 square meters. It is composed of a large space workshop, two high-level warehouses and five independent street-style buildings. It is planned to build the South China Fashion Design Center. Fashion culture as the core, to build the first fashion LOFT community in Xiamen, through the fashion show field, creative design office space, artistic creation and communication space, fashion commercial district, fashion communication, life experience and creative office-based, exhibition And public leisure, supplemented by functional, comfortable and natural cultural and creative park.

Huamei Cigarette Factory in the regeneration of the design from the whole to the local, practices also will continue to change. Mainly used is the spatial integration method, primary and secondary comparison method, facade induction method, structural expression method, memory extension method. The use of various methods is not independent existence, with the interaction and combination of the final form of the transformation of the results of the system.

Spatial Integration Method. "Dredge" on the space in series and through. Huamei Cigarette Factory have main plant, ancillary equipment and large warehouse buildings, such as a combination. Transformation of the design of a central axis of things is through the Huamei Cigarette Factory, forming a nearly 150-meter-long internal commercial space, display space, office space as one of the functional axis. Through the central axis of the scattered functions of the organic combination, that is, to strengthen the link between the various functions of space activities also enrich the diversity. The central axis virtually dredge the traffic relations between things, while parallel with the axis there is a thing through the inner streets, as well as two through the north and south of the street, the formation of "well" shape of the spatial pattern, this east-west traffic and function To obtain an effective series and distribution.

"Replace" function of the orderly conversion. In the transformation of the monomer, the original coal-fired boiler room for functional combination, the formation of display, office and dining as one of the large cultural activities space, the space can hold a variety of exhibitions, exchanges and other activities. The internal space is as much as possible to retain the original architectural form, with a strong sense of space space. In the southern base of the original a small ancillary space has been transformed into a creative office space, the original building floor low lighting poor in the transformation of the space to expand the style and facade transformation, the effective combination of functions and Conversion.

Primary and Secondary Comparison Method. "space" of the hierarchical relationship between space. In the transformation of regional space, using different spatial modeling with a dotted line is to form a rich space node. The eastern office area of the factory area is nearly one floor higher than the main plant area. The design uses the height difference to express the markings in the multi-storey office building façade, and molds the regional east-west axis to mark the area. Space primary contrast (Figure 1). The main entrance plaza next to the edge of the irregular shape of the fashion show field construction, the use of contrast and the main plant material, in the whole plant is particularly prominent, highlighting the entrance of the building primary and secondary relationships. 


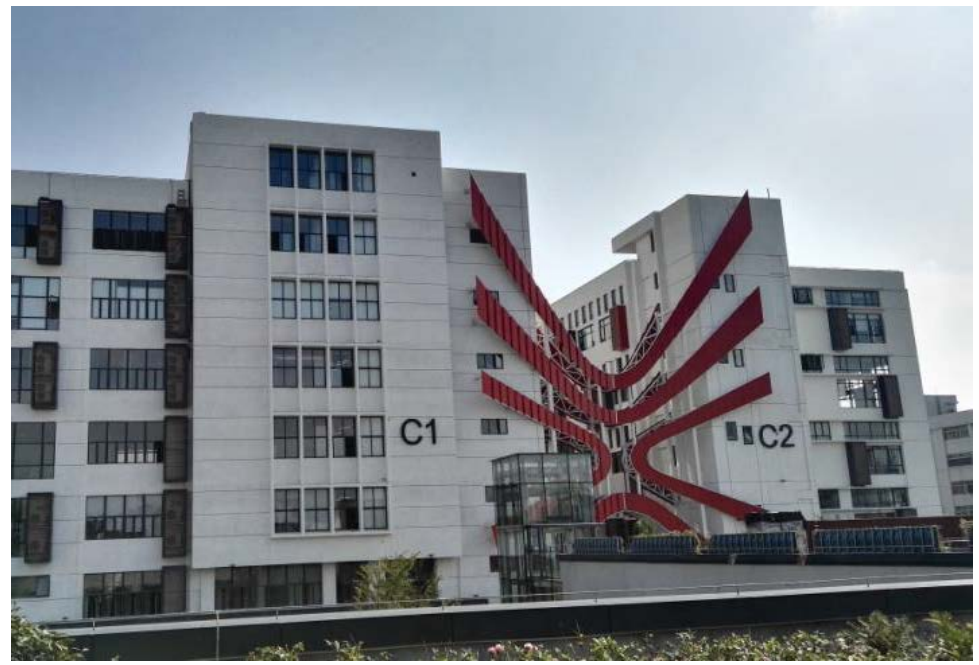

Fig. 1 Space primary contrast

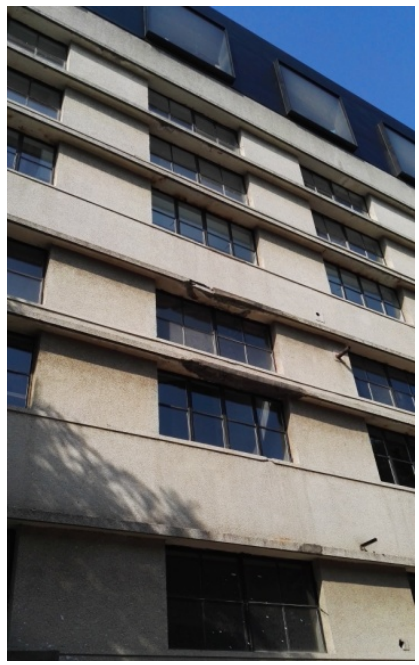

Fig. 2 Keep the original material

"Material" the use of different materials than. The use of the original wall material and the new addition of other materials combined with the skin. Two warehouses and along the street to coal-fired boiler room as the center of the annex as a whole to retain the original material as the main space material tone (Figure 2), on the basis of the introduction of modern industrial materials such as perforated aluminum, cement brick, Steel, glass curtain wall, cement paint and so on. In breaking the original site of the material mechanism at the same time is to give up the industrial plant of modern temperament, virtually role-shifting.

Facade Induction Method. "Innovation" to add and expand new functional space. Expansion of industrial buildings is a common approach, the expansion of the architectural form of the original building can enrich the form and facade. Hua space expansion is the main entrance square at the large fashion show field (Figure 3), the facade with perforated aluminum, the use of variant form of modeling combined with repeated design practices, the formation of a strong visual impact of the entrance image, a beautiful space Of the main signs of one form.

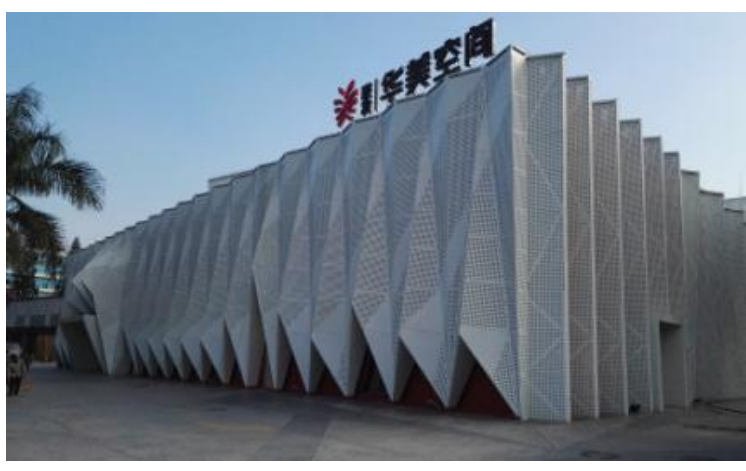

Figure 3 main entrance elevation modeling

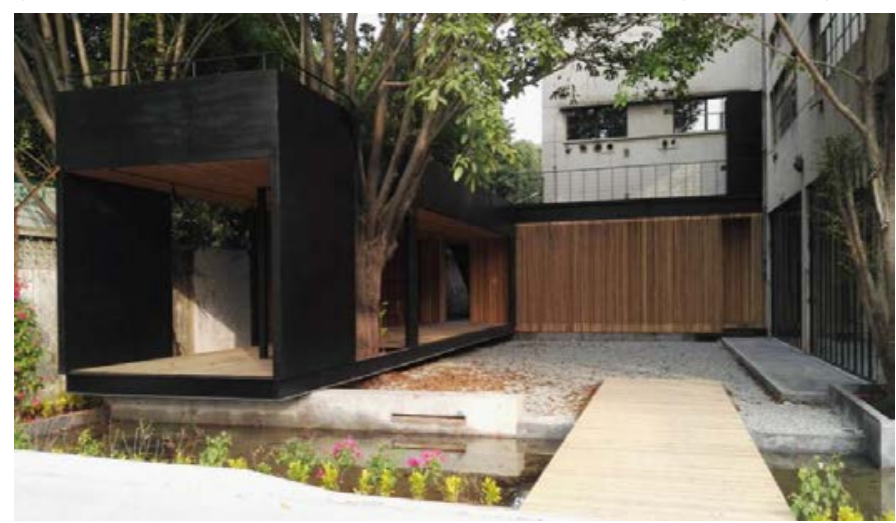

Figure 5 expansion of coal-fired boiler room

"Old" reserved part of the building facade. Industrial architecture is characterized by large-span

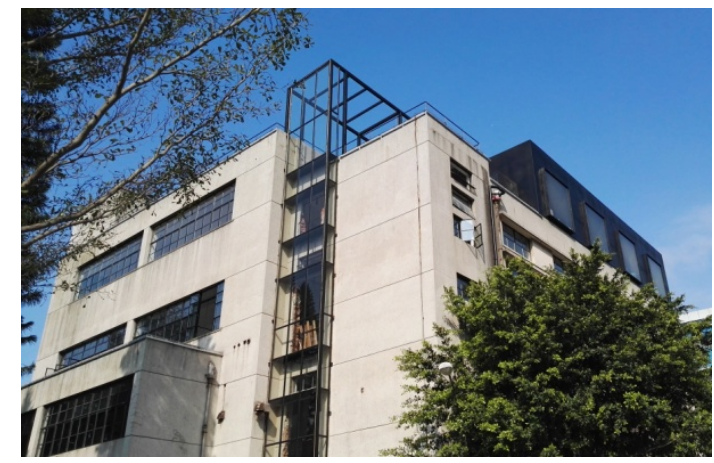

Figure 4 The old and new material combination

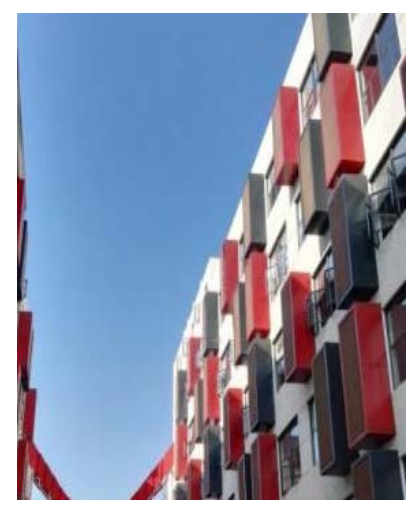

Figure 6 Creative public building facade
architecture is characterized by large-span 
structural beams and columns in the form, in the facade and the internal structure of the performance is particularly prominent. Huamei Cigarette Factory, the original large-scale transformation of the plant to retain the shape of column network pattern. In particular, coal-fired boiler room facade in addition to the use of window and shape processing frame glass structure, other areas still retain the original washing stone rough facade mechanism, forming a strong sense of space contrast (Figure 4). Walking in the production areas you will find in the different corner of the building, such as steel beams and other damaged industrial components retained as part of the building show that these old structures are all evoking the memory of industrial civilization.

"Comparison" material contrast. The form of industrial space has a strong sense of indifference, rough mad shape and water chestnut lines have refused thousands of miles away feeling. In the transformation of design, such as coal-fired boiler room on the north side of the expansion of the building pieces of wood-based, will be surrounded by a tree which form a Smart jump space level (Figure 5). The two office buildings in the east are fenestrated, and red, blue and other forms are used to enhance the contrast with the material of the original industrial building, and enrich the space temperature (Fig. 6). Commercial Street facade to retain the original plant gray walls, the use of modern cement brick patchwork approach to the concave and convex morphology processing, in the light and shadow of the formation of a unique facade layering.

Structural Expression Method. "Reconstruction" of space for structural integration. The original main plant in the transformation can be effectively used in the horizontal direction on the flexible division of space; in the vertical direction to increase or decrease loft, breaking the uniform spatial form, the construction of the atrium space ${ }^{[4]}$. In addition, due to the characteristics of industrial building frame structure, building legislation

Surface and roof of the transformation of greater flexibility, can form a unique architectural image ${ }^{[5]}$. Huamei Cigarette Factory in the transformation of the design process, although the whole picture to retain the original building structure, the main structure of the original continuation of the original concrete frame structure of large-span at the same time, the internal structure of the building reinforcement, segmentation and addition and subtraction of internal space for space reconstruction And conversion. The coal-fired boiler room forms the LOFT-style corridor and resting platform in the air by the steel structure high-altitude way, transforms the original single storage and the coal function and the equipment to form the function space which the exhibition, the gathering and the dining integrates (Fig. 7).

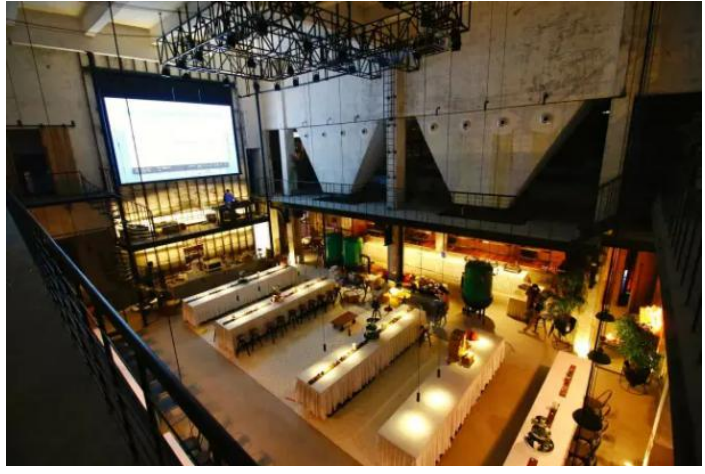

Figure 7 Coal-fired boiler room inside

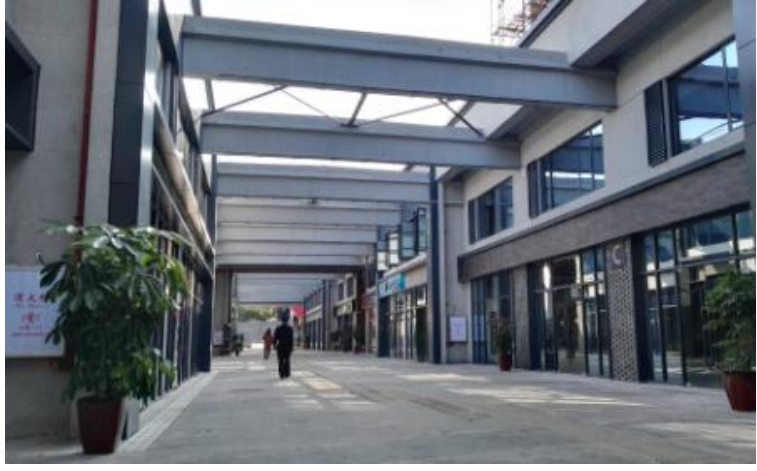

Figure 8 The original frame structure is retained

"Symbol" a symbol of the form of the times. Old industrial building large span, high floor, rough skin is not only a cultural symbol of the industrial age, but also to show the city's historical style. Experienced decades of wind and rain vicissitudes, the old industrial buildings inside the industrial equipment, industrial materials, rivet skin, metal doors and other dusty people old stories, old feelings (Figure 8). Reconstruction of the building not only brings new use value, but also makes the ordinary people's memories to find the end. In the process of regenerative remodeling and the use of materials, Huamei Cigarette Factory continually builds up the internal structure of the building and adds new ideas. Through the contrast of the old and new functional structures, styles, materials and colors, the original building structure is continually conveyed, and the construction is 
different from the past.

Memory Extension Method. "Reserved" to use the original equipment and raw materials. In the transformation of the entire space, coal-fired boiler room equipment and space mechanism is to retain the Huamei Cigarette Factory one of the biggest bright spot. Into the internal space of coal-fired boiler room, showing a gradient in the black spots on the wall, it is the original coal-fired boiler room in the coal-fired process of settling down the ash. In the ground and top are retained at the time to use some of the coal and emissions equipment, modeling exaggerated and has a sense of the times, whether the equipment or mechanisms to retain a certain extent, and the plant history of memory.

"Extension" gives more Imaginary space. It mainly reflected in the region of some decorative shapes and sketches. In the east-west axis of the east of the office area there is a dynamic spiral sculpture, the use of industrial steel materials, the contents of the complex is the city buildings, forming a radial form. At the same time in the main office building to have a large red steel structure of Huamei cultural and creative LOGO shape, its structure is a typical industrial civilization products, the use of the structure of the two buildings linked together in the region outside the formation of the regional focus of the visual And image modeling. The use of industrial structure and raw materials supplemented by exaggerated artistic approach, the content of space to be extended, giving more imaginary space.

"Narrative" space text display historical process. This straightforward narrative is also a lot of old urban areas and old industrial plants will be transformed after the approach taken. Using the transformation of coal-fired boiler room floor space to showcase the history of the region and the transformation process, while office and commercial street center axis space surface pavement with translucent color steel plate, with the laser engraving on the text above, Space, the whole construction and development history. This narrative technique is intuitive and clear, can quickly let the participants feel the region within the historical evolution.

\section{Conclusion}

Regeneration and renewal of industrial buildings is not a new topic, each city needs to be adapted to local conditions and determine its regeneration and renewal methods according to the mechanism of the city, the human environment and the needs of the market. With the development of the times, Huli district is also facing the dilemma of industrial renewal and upgrading. Therefore, how to transform the "barrier" of the existing industrial building transformation into the space carrier and power of new industry development is an urgent problem to be solved. Through summing up and researching the method of Huamei cigarette factory rebuilding design, we can find the commonality from individuality, summarize the typical technique from the reconstruction and draw lessons to facilitate the regeneration and renewal of the industrial buildings in other areas of Huli district. Protection and regeneration of industrial sites has a guiding effect.

\section{Acknowledgements}

The Ministry of Construction of the Ministry of Construction Science and Technology Project

No. 2016, No. 96

Fujian Department of Education, Fujian Province, young teachers in education research project

No. JAS150782 Haixi industrial site renewal and cultural creative space form research

\section{References}

[1] Cai Xianyong. Huli Industrial Zone, Xiamen City, industrial function transformation countermeasures [D]. Xiamen University, 2008

[2] Shi Zheng. Effective Pathway of the Development of Cultural Creative Industry Agglomeration in the Urban Agglomeration of the Yangtze River Delta: From the Perspective of Cultural 
Creative Industry Park in Shanghai, Ningxia and Hangzhou [J]. Lanzhou Academic Journal, 2011

[3] Liu Yao. Old industrial plant re-use [J]. Industrial Construction 2011 (2): 16-20

[4] Tian Yan, Dong Feifei. "Iron and Steel Green Boat" Study on the Sustainable Utilization of Industrial Heritage in Hanyang Steel Plant [J]. Central China Architecture, 2013

[5] Shang Xiaoxi, Hao Bo. Transformation of Conventional Old Industrial Buildings [J]. Urban Problems, 2006 (3): 44-47 